\title{
Accumulation of Iron-binding Phenolic Acids by Actinomycetales and Other Organisms Related to the Mycobacteria
}

\author{
By C. RATLEDGE AND M. A. CHAUDHRY \\ Department of Biochemistry, The University, \\ Hull, HU6 7 RX, Yorkshire
}

(Accepted for publication 2 March I97I)

\begin{abstract}
SUMMAR Y
After growth of representatives of eight genera in the order Actinomycetales and two others related taxonomically to Mycobacterium under iron-deficient conditions, the following compounds were found in the media: salicylic and phenylacetic acids, but no mycobactin, with Thermoactinomyces vulgaris; 2,3dihydroxybenzoic acid with Corynebacterium equi, Mycococcus sp., Nocardia opaca and Streptosporangium rubrum; a conjugate of 2,3-dihydroxybenzoic acid and 3,4-dihydroxybenzoic acid were also found with $S$. rubrum. Unidentified compounds giving a positive reaction to $\mathrm{FeCl}_{3}$ were found after growth of Dactylosporangium thailandensis and Propionibacterium shermanii. No iron-binding compounds were detected with Actinoplanes phillippinensis, Micromonospora sp. and Streptomyces albus.
\end{abstract}

\section{INTRODUCTION}

At least three types of hydroxybenzoic acid are excreted by bacteria under conditions of iron deficiency: (I) 2,3-dihydroxybenzoic acid and its conjugates with amino acids (Ito \& Neilands, I958; Dyer, Heding \& Schaffer, 1964; Ratledge, I964; Brot, Goodwin \& Fales, I966; Corbin \& Bulen, I969; Korth, 1970; O’Brien \& Gibson, I970; Pollack \& Neilands, I970); (2) 3,4-dihydroxybenzoic acid (Chao, Hawkins \& Williams, 1967; Bakshi \& Williams, 1969; Cagle \& Williams, I969); and (3) 2-hydroxybenzoic acid (salicylic acid) and 6-methylsalicylic acid (Ratledge \& Winder, I962, I966; Dhople, Morrison \& Hanks, 1965).

The acids of the first two groups are produced by a variety of bacteria but salicylic acid and 6-methylsalicylic have only been found among mycobacteria. This generalization is, however, based on the examination of only a few species. Indeed, the only member of the Actinomycetales, of which Mycobacterium is a member, to be examined before this work was Streptomyces griseus, which accumulated 2,3-dihydroxybenzoic acid when deficient in iron (Dyer et al. 1964).

Organisms belonging to the Actinomycetales and the related genera of Corynebacterium and Propionibacterium (Jensen, 1966; Lechevalier \& Lechevalier, 1967) have been examined to see if the production of salicylic acid is restricted and, if so, whether it would provide a useful character for the identification of mycobacteria.

\section{EXPERIMENTAL}

Organisms. The following organisms were used: Actinoplanes phillippinesis ATCC 12427; Corynebacterium equi (obtained from Dr P. J. Brennan, Trinity College, Dublin University); Dactylosporangium thailandensis CUB 429 (from Mr T. Cross, curator of the Actinomycete Culture Collection, Bradford University); Micromonospora sp. CUB 26; Mycococcus sp. 
ATCC 13556; Nocardia opaca NCIB 9409; Propionibacterium shermanii NCIB 5964; Streptomyces albus IMI 52766 (from Commonwealth Mycological Institute, Kew, Surrey); Streptosporangium rubrum CUB I59; Thermoactinomyces vulgaris CUB 76 . All cultures were maintained on nutrient agar slopes except $C$. equi, which was maintained on slopes of Loeffler's serum. All organisms were subcultured monthly.

Medium and removal of trace metals. The basal medium which was used for cultivation of most of the organisms contained $\left(\mathrm{NH}_{4}\right)_{2} \mathrm{SO}_{4}(2 \mathrm{~g}$. $)$ and $\mathrm{KH}_{2} \mathrm{PO}_{4}$ (9 g.) in I 1. distilled water made to $\mathrm{pH} 7.5$ with $\mathrm{NaOH}$. Trace metals were removed by autoclaving the medium with alumina (Donald, Passey \& Swaby, 1952). After removal from the alumina, the medium was adjusted to $\mathrm{pH} 6.8$ with $2 \mathrm{M}-\mathrm{H}_{2} \mathrm{SO}_{4}$ and dispensed either in $90 \mathrm{ml}$. amounts in $250 \mathrm{ml}$. conical flasks, $720 \mathrm{ml}$. in 21 . conical flasks or $\mathrm{I} 440 \mathrm{ml}$. in 41 . conical flasks and autoclaved for $15 \mathrm{~min}$. at $12 \mathrm{I}^{\circ}$. This medium was supplemented with glucose, from a $30 \%(\mathrm{w} / \mathrm{v})$ solution previously treated with alumina to remove trace metals, and $\mathrm{MgSO}_{4} \cdot 7 \mathrm{H}_{2} \mathrm{O}$ to $30 \mathrm{~g} . / 1$. and $0.4 \mathrm{~g}$./1. respectively.

The following nutrients were added to $0 . \mathrm{I} \mathrm{g}$./l. from alumina-treated solutions as required by the organism: for Actinoplanes phillippinesis, peptone, yeast extract, malt extract, beef extract and tryptone; for Dactylosporangium thailandensis and Micromonospora sp., peptone and malt extract; for Mycococcus sp., peptone; and for Streptosporangium rubrum and Thermoactinomyces vulgaris, peptone and yeast extract.

For cultivation of Corynebacterium equi in liquid medium the medium of Brennan, Lehane \& Thomas (1970) was used. Glucose was sterilized separately from the remainder of the medium. Both parts of the medium were autoclaved with alumina to remove trace metals and finally dispensed in $100 \mathrm{ml}$. amounts in $250 \mathrm{ml}$. conical flasks.

For cultivation of Nocardia opaca the medium contained glycerol $(20 \mathrm{ml}$ ), monosodium L-glutamate (0.24 g.), $\mathrm{KH}_{2} \mathrm{PO}_{4}\left(2.5 \mathrm{~g}\right.$.), $\mathrm{NH}_{4} \mathrm{NO}_{3}$ ( $\mathrm{I}$ g.), in distilled water to $\mathrm{I} 1$. and the $\mathrm{pH}$ was adjusted to $7 \cdot 5$ with $\mathrm{NaOH}$. Trace metals were removed by alumina treatment and the $\mathrm{pH}$ was adjusted to 6.8 with $2 \mathrm{M}^{-} \mathrm{H}_{2} \mathrm{SO}_{4}$. The medium was finally dispensed in $100 \mathrm{ml}$. amounts in $250 \mathrm{ml}$. conical flasks; $\mathrm{MgSO}_{4} \cdot 7 \mathrm{H}_{2} \mathrm{O}$ at $0.4 \mathrm{~g}$./l. was included immediately prior to inoculation.

Propionibacterium shermanii was grown on medium which contained glucose (5 g.), yeast extract $(5 \mathrm{~g}$.), peptone $(5 \mathrm{~g}$.), sodium thioglycollate $(\mathrm{I} \cdot \mathrm{\circ} \mathrm{g}$.) in distilled water to $\mathrm{I} 1 ., \mathrm{pH}$ adjusted to 7.5 with $\mathrm{NaOH}$. After treatment with alumina the medium was adjusted to $\mathrm{pH} 6 \cdot 8$, dispensed in $\mathrm{I} \cdot 51$. amounts in 21 . flasks and sterilized by autoclaving. The medium was supplemented with the following $(\mathrm{mg} . / 1$.$) : calcium pantothenate (\mathrm{I} \cdot \mathrm{O})$, thiamine hydrochloride ( $\mathrm{I} \cdot \mathrm{O})$ and biotin ( $\mathrm{I} \cdot 0)$. Each flask was fitted with a sintered glass disc to allow $\mathrm{N}_{2}+\mathrm{CO}_{2}(95: 5, \mathrm{v} / \mathrm{v})$ to be introduced at about $20 \mathrm{ml}$./min. throughout incubation.

Streptomyces albus was grown on medium which contained $\mathrm{KH}_{2} \mathrm{PO}_{4}\left(5 \mathrm{~g}\right.$.), $\mathrm{NH}_{4} \mathrm{NO}_{3}$ (2 g.), L-asparagine (I g.)/1. distilled water, $\mathrm{pH}$ adjusted to 7.5 with $\mathrm{NaOH}$. After treatment with alumina the medium was adjusted to $\mathrm{pH} 6 \cdot 8$, dispensed in $\mathrm{I} 80 \mathrm{ml}$. amounts in $500 \mathrm{ml}$. conical flasks and sterilized by autoclaving. It was supplemented with $20 \mathrm{ml} / \mathrm{l}$. of $20 \% \mathrm{w} / \mathrm{v})$ alumina-treated glucose solution; yeast extract and peptone, both as solutions previously alumina-treated, were added to $0 \cdot 1 \mathrm{~g} . / 1$.

Metal ions added to media. The following metal ions were added to all media: $\mathrm{ZnSO}_{4} \cdot 6 \mathrm{H}_{2} \mathrm{O}$, $0.46 \mu \mathrm{g}$. $\mathrm{Zn} / \mathrm{ml}$.; $\mathrm{MnSO}_{4} .4 \mathrm{H}_{2} \mathrm{O}, 0.28 \mu \mathrm{g}$. Mn $/ \mathrm{ml}$.; $\mathrm{FeSO}_{4} .7 \mathrm{H}_{2} \mathrm{O}, 0.05$ to $5 \mu \mathrm{g}$. Fe $/ \mathrm{ml}$. Growth was usually iron-deficient when the final concentration was $0 \cdot 1 \mu \mathrm{g}$. Fe $/ \mathrm{ml}$. or less ('low-iron' medium) and iron-sufficient (or normal) at 2 to $5 \mu \mathrm{g}$. Fe/ml. ('high-iron' medium).

Inocula and growth. Half or I \% inocula were prepared from cultures grown on liquid media with $2 \mu \mathrm{g}$. $\mathrm{Fe}^{2+} / \mathrm{ml}$. With Actinoplanes phillippinensis, Streptomyces albus and Thermo- 
actinomycetes vulgaris, where growth was either in the form of clumps or as a pellicle, inocula were prepared by shaking a few loopfuls of the clumps or pellicle with glass balls (undrilled, B.D.H. Chemicals Ltd, Poole, Dorset).

Condition of growth. All cultures were at $30^{\circ}$ except Corynebacterium equi, which was incubated at $37^{\circ}$, and Thermoactinomyces vulgaris, which was at $50^{\circ}$. Cultures were not usually shaken but Micromonospora sp. and Streptosporangium rubrum were also incubated in an orbital shaker.

Harvesting of cultures and determinations of bacterial dry weights. Cultures were centrifuged or, where growth was in pellicle-form, filtered through a sintered glass filter (no. 2 porosity); organisms were washed twice in distilled water before being dried over $\mathrm{P}_{2} \mathrm{O}_{5}$ under vacuum to constant weight.

Isolation of compounds from culture media. The medium was acidified with $5 \mathrm{M}-\mathrm{H}_{2} \mathrm{SO}_{4}$ to $\mathrm{pH} 3$ and extracted three times with equal volumes of diethyl ether. The ether extract was dried over $\mathrm{MgSO}_{4}$, filtered, evaporated in a rotary evaporator to $\mathrm{I} \cdot 0$ to $0.5 \mathrm{ml}$., and the concentrate was chromatographed on Whatman 3 MM or no. I 7 paper using solvent system 6 (see below) in an ascending direction. Compounds were visualized under u.v. $\operatorname{light}(253.7 \mathrm{~nm}$.) and the fluorescent areas noted. Strips of each chromatogram were sprayed with $2 \% \mathrm{FeCl}_{3}$ in $0 . \mathrm{I} \mathrm{M}-\mathrm{HCl}$. Areas with prominent fluorescence or giving a colour to the spray reagent were twice eluted by standing in ether-ethanol-water ( $3: \mathrm{I}: \mathrm{I}$, by vol.) for 6 to $8 \mathrm{~h}$. These extracts were then further investigated.

Paper chromatography on Whatman no. I paper was used in an ascending direction with the following solvent systems: I, methanol+butan-I-ol+benzene+water $(2: \mathrm{I}: \mathrm{I}: \mathrm{I}$, by vol.); 2, butan-I-ol + pyridine + aq. $\mathrm{NH}_{3}$ (sp.gr. $0 \cdot 880$ ) + water $(4: 8: 5: 3$, by vol.); 3 , butan2-one + 2-methylpropan-2-ol + water (2:2: I, by vol.); 4, butan-I-ol + benzene + ethanol + aq. $\mathrm{NH}_{3}$ (sp.gr. 0.880$)(5: 2: \mathrm{I}: 2$, by vol.); 5, butan-I-ol + acetic acid + water ( $4: \mathrm{I}: \mathrm{I}$, by vol.); 6, propan-2-ol +aq. $\mathrm{NH}_{3}$ (sp.gr. $0 \cdot 880$ ) + water ( $8: \mathrm{I}: \mathrm{I}$, by vol.).

Spray reagents. The composition of chromatography sprays were as given by Dawson, Elliot, Elliot \& Jones (I959), Smith (I960) or McGeer, Robertson \& McGeer (I96I).

Mass spectra were determined in a high resolution mass spectrometer (model MS 902, A.E.I. Scientific Apparatus Ltd, Urmston, Manchester).

Absorption spectra were determined using a recording u.v. spectrophotometer (model SP 800, Unicam Instruments Ltd, Cambridge) fitted with microcuvettes when necessary. Spectra were usually determined in ethanol, $\mathrm{O} \cdot \mathrm{I} \mathrm{M}-\mathrm{NaOH}$ and $\mathrm{o} \cdot \mathrm{I} \mathrm{M}-\mathrm{HCl}$.

Identification of individual compounds isolated from culture filtrates. Salicylic acid (from Thermoactinomyces vulgaris) had $R_{F}$ values coincident with authentic salicylic acid after paper chromatography in solvent systems I, 2 and 3. Paper chromatography using ethanol+xylene + toluene + aq. $\mathrm{NH}_{3}$ (sp.gr. 0.880$)(5: 4: 2: \mathrm{I}$, by vol.) distinguished the isolated material $\left(R_{F} 0.27\right)$ from 6-methylsalicylic acid $\left(R_{F} 0.34\right)$ (obtained as a gift from Dr G. A. Snow, I.C.I. Ltd, Alderley Park, Macclesfield). Identification of the isolated material was confirmed by reactions to a number of reagents, u.v. and mass spectrometry. Mass measurement of the parent ion of the isolated material gave I38.03I69: the expected value for $\mathrm{C}_{7} \mathrm{H}_{6} \mathrm{O}_{3}$ was $\mathrm{I} 38.03194$.

2,3-Dihydroxybenzoic acid (from Corynebacterium equi, Mycococcus sp., Nocardia opaca and Streptosporangium rubrum). The $R_{F}$ values of the isolated materials after chromatography using solvent systems I, 4 and 5 were always within an $R_{F}$ of 0.03 of the authentic sample. Extinction maxima of the isolated compounds and reactions to various spray reagents were the same as those obtained with an authentic sample (see Ratledge, I967). Mass spectra of the four isolated samples of 2,3-dihydroxybenzoic acid and an authentic 
sample showed similar fragmentation patterns. Mass measurement of each parent ion gave I 54.02575 for the material from $C$. equi : I 54.02665 for that from Myococcus sp.; I 54.02499 for that from $N$. opaca; and 154.02575 for that from $S$. rubrum. For $\mathrm{C}_{7} \mathrm{H}_{6} \mathrm{O}_{4}$ the expected value of the parent ion was $154^{\circ} 02660$.

Conjugate of 2,3-dihydrozybenzoic acid (from Streptosporangium rubrum) had a blue fluorescence under u.v. light and turned blue when sprayed with $\mathrm{FeCl}_{3}$. Both these properties were similar to those of 2,3-dihydroxybenzonic acid. However, it had an $R_{F}$ value of 0.75 after chromatography on Whatman $3 \mathrm{MM}$ paper using solvent system $\mathbf{I}$, whereas 2,3-dihydroxybenzoic acid had an $R_{F}$ value of 0.66 . The extinction maxima of the isolated compound in $0 . \mathrm{I} \mathrm{M}$ citric acid-NaOH buffer at pH 6.0 were at $232 \mathrm{~nm} ., 250 \mathrm{~nm}$. (shoulder) and $309 \mathrm{~nm}$. (for authentic 2,3-dihydroxybenzoic acid the maxima were at 243 and $307 \mathrm{~nm}$.) and in $0^{\circ} \mathrm{I} \mathrm{M}$-tris $\mathrm{HCl}$ buffer, $\mathrm{pH} 8.0$, were at $230 \mathrm{~nm}$., $256 \mathrm{~nm}$. (slight shoulder only) and $329 \mathrm{~nm}$. (for authentic 2,3-dihydroxybenzoic acid the maxima did not shift and remained at $24 \mathrm{I}$ and $308 \mathrm{~nm}$.). The shift observed for the isolated material is similar to that observed for 2,3-dihydroxybenzoylserine (Luke, I970). A dry sample of the isolated material was hydrolysed in $6 \mathrm{M}-\mathrm{HCl}\left(0.5 \mathrm{ml}\right.$.) at $140^{\circ}$ in a sealed glass tube for $16 \mathrm{~h}$. The cooled solution was adjusted to a value between $\mathrm{pH} \mathrm{I}$ and 3 with $\mathrm{IO} \mathrm{M}-\mathrm{NaOH}$ and extracted with ether $(3 \times \mathrm{I} \mathrm{ml}$. $)$. The ether extract was evaporated to near dryness and after chromatography in solvent system 62,3 -dihydroxybenzoic acid was identified by its fluorescence, $R_{F}$ value and reactions to a number of reagents $\left(\mathrm{FeCl}_{3}\right.$, Arnow's reagent, diazotized sulphanilic acid and diazotized $p$-nitroaniline).

Phenylacetic acid (from Thermoactinomyces vulgaris) had no fluorescence under u.v. light and was detected by $0.1 \%$ bromocresol green after chromatography in solvent system 2 . It was identified by its u.v. and mass spectra: the isolated material gave a parent ion of mass I 36.05249; the expected value for $\mathrm{C}_{8} \mathrm{H}_{8} \mathrm{O}_{2}$ was I 36.05242 . Mass spectra of $o$-, $m$ - and $p$-toluic acids (which are isomeric with phenylacetate) were not the same as the isolated material. The methyl ester of isolated material was analysed by g.l.c. and gave the same retention time as authentic methyl phenylacetate.

3,4-Dihydroxybenzoic acid (from Streptosporangium rubrum) was identified by its fluorescence, reaction to various reagents, chromatographic mobility and u.v. spectra (see Ratledge \& Winter, 1966).

Extraction of Thermoactinomyces vulgaris for mycobactin. Bacteria were dried to a constant weight over $\mathrm{P}_{2} \mathrm{O}_{5}$, extracted with ethanol (White \& Snow, 1968) and the extract $+\mathrm{FeCl}_{3}$ was further extracted into chloroform which was then taken to dryness. The residue was dissolved in $0.5 \mathrm{ml}$. methanol and its extinction at $450 \mathrm{~nm}$. was determined. It was separated by t.l.c. on silica-gel $\mathrm{G}$ using cyclohexane + 2-methylpropan-2-ol+propan-1,2-diol (40: I0: I, by vol.) (White \& Snow, I968). Authentic mycobactin s (prepared by extraction of Mycobacterium smegmatis; see Snow, 1965) was chromatographed simultaneously. The isolated material was viewed under u.v. light and also sprayed with $25 \mathrm{mM} \mathrm{NH}_{4} \mathrm{VO}_{3}+6 \mathrm{M}-$ $\mathrm{HCl}(\mathrm{I}: \mathrm{I}, \mathrm{v} / \mathrm{v})$ (White \& Snow, I968).

\section{RESULTS AND DISCUSSION}

Table I summarizes the growth of the various organisms studied and the compounds which were identified after extraction of media. Although 2,3-dihydroxybenzoic acid was identified after acid hydrolysis of the conjugate isolated from the 'low-iron' medium of Streptosporangium rubrum, the attempt to characterize the other component by preparation of a dansyl derivative (Boulton \& Bush, 1964) was unsuccessful. Both Actinoplanes phillip- 

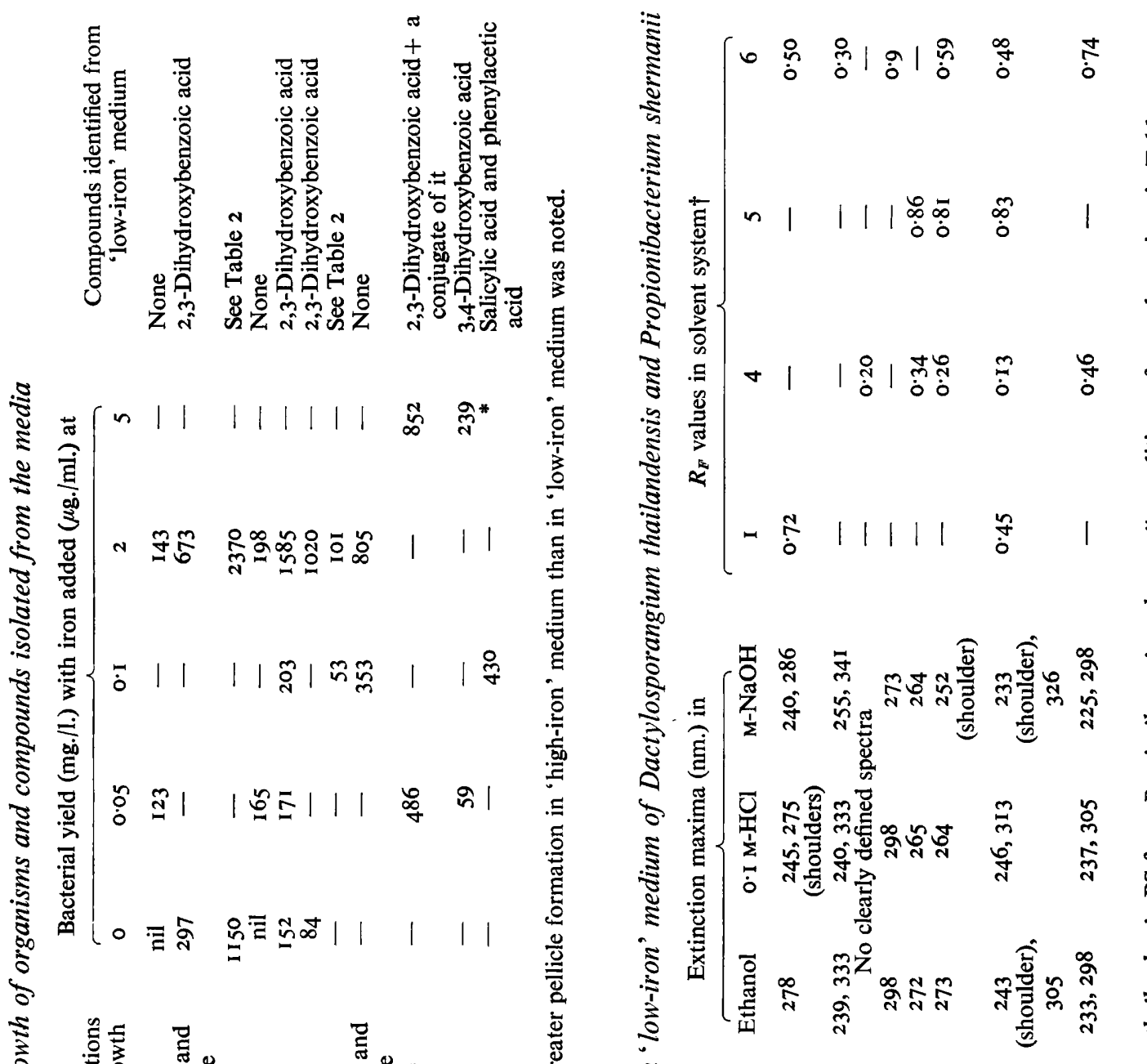

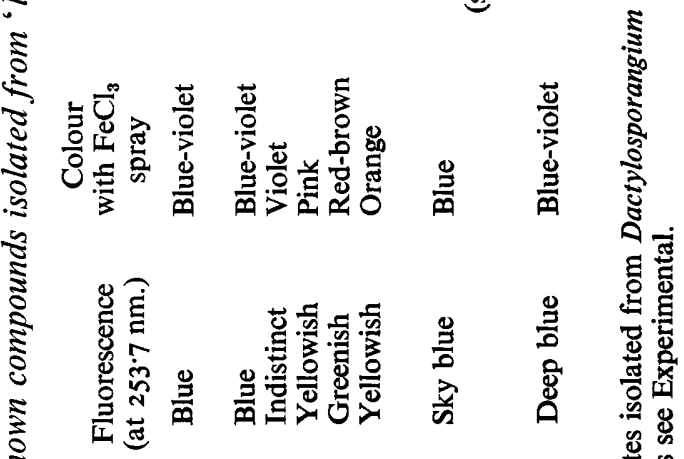

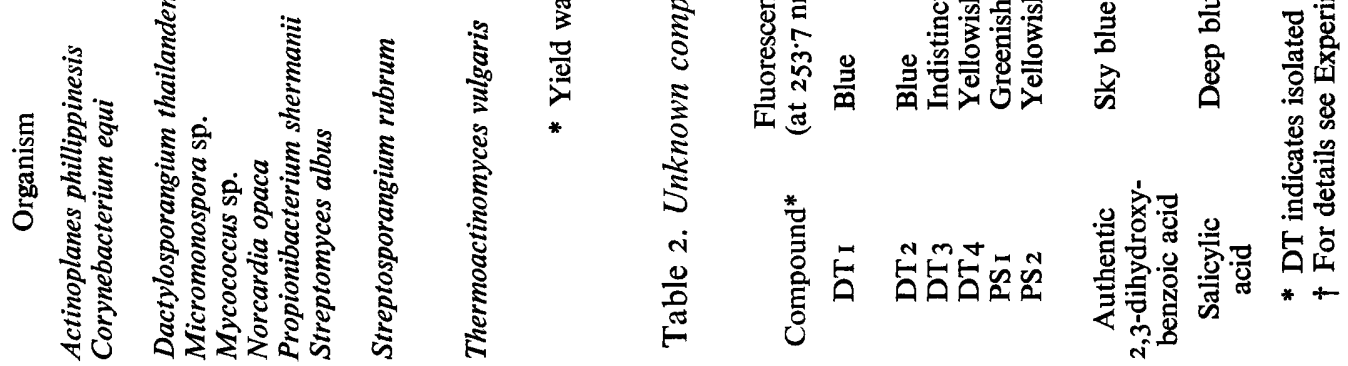


pinesis and Micromonospora sp. showed only a small difference in yield between 'low-iron' and 'high-iron' conditions but did not grow when iron was omitted. Apparently the iron requirement of each organism was satisfied by a small concentration (cf. Chesters \& Rolinson, 195I). The components isolated from all 'low-iron' media were not detected in highiron' conditions.

Several compounds reacting with $\mathrm{FeCl}_{3}$ were isolated from 'low-iron' media of Dactylosponangium thailandensis and Propionibacterium shermanii, but were not present in sufficient amount to permit identification (Table 2). Compound DT I was probably an $o$-dihydric phenolic acid as, in addition to the properties given in Table 2, it became yellow-red with Arnow's reagent, a reagent specific for this group of compounds.

Salicylic acid had previously only been found in culture filtrates of Mycobacterium smegmatis and $M$. tuberculosis. It is always associated with an intracellular iron-chelating compound, mycobactin, of which salicylic acid forms a part (Snow, 1970). The occurrence of mycobactin may be useful as an aid to the identification of mycobacteria (Snow, 1970; Snow \& White, 1969) but this would not be so if Thermoactinomyces vulgaris produced a similar compound. Because of the occurrence of salicylic acid in medium of the latter organism, the occurrence of mycobactin was sought most carefully. About $650 \mathrm{mg}$. of dry T. vulgaris, obtained from I.51. of 'low-iron' medium, was extracted for mycobactin. No material was found which chelated with iron to give a coloured product, or had an extinction maxima at $450 \mathrm{~nm}$. After thin-layer chromatography of the entire material which was soluble in methanol, no fluorescent area or area reacting to $\mathrm{NH}_{4} \mathrm{VO}_{3}$ spray reagent could be seen.

The occurrence of salicylic acid in culture filtrates of Thermoactinomyces vulgaris as well as in Mycobacterium smegmatis and $M$. tuberculosis is probably fortuitous as the two different genera have little taxonomic or evolutionary connexion (Cross, I968).

The role of salicylic acid in biosynthesis in the two genera is undoubtedly different. With Mycobacterium smegmatis salicylic acid is taken up from the medium and used in the biosynthesis of mycobactin (Ratledge \& Hall, 1970). Such a relationship cannot occur in T. vulgaris as this organism lacks mycobactin. The formation of salicylic acid in this latter organism parallels that of 2,3-dihydroxybenzoic acid in other organisms (such as Escherichia coli and Klebsiella aerogenes) where there is no intracellular counterpart to the extracellular iron chelator. The function of all these iron-chelating compounds could be the same, namely to transport iron into the cell (cf. Peters \& Warren, I968; Wang \& Newton, I969; Downer, Davis \& Byers, 1970). Their increased accumulation under iron-deficient growth conditions is consistent with this view.

The production of salicylic acid by bacteria is not common. The compound was not found in Mycococcus sp., which is currently classified (Breed, Murray \& Smith, I957) as a genus of the family Mycobacteriaceae, the only other member of which is Mycobacterium itself. Nor was it found in Corynebacterium equi or Nocardia opaca, two species from genera close to Mycobacterium (Lechevalier \& Lechevalier, 1967). In both these species, and in Mycococcus sp. and Streptosporangium rubrum, 2,3-dihydroxybenzoic acid was the ironbinding phenolic acid produced. The distribution of this compound may therefore be as widespread among the Actinomycetales as it is among the Eubacteriales (see Introduction).

The apparent absence of an iron-binding phenolic acid in the culture media of some of the organisms studied here may be due to an insufficiently sensitive means of detection. However, these compounds might be replaced functionally by ferrioxamines (see Neilands, I966) which have been isolated from several genera of the Actinomycetales: from species of Micromonospora, Nocardia, Streptomyces and Streptosporangium (Zahner, Bachmann, 
Hutter \& Nuesch, 1962). Although 2,3-dihydroxybenzoic acid occurs in two of these genera (i.e. in Nocardia and Streptosporangium) and this compound has also been isolated from Streptomyces (Dyer et al. 1964), it is not possible to say whether ferrioxamines are simultaneously formed along with phenolic acids. The absence of any iron-binding phenolic acid in Actinoplanes phillippinesis and Micromonospora sp. could perhaps be attributed to prior formation of a ferrioxamine. Further investigations may show whether the functions of the ferrioxamines and the phenolic acids are the same, and, if so, whether their formations are mutually exclusive.

We thank Dr R. B. Moyes, Department of Chemistry, University of Hull, for his assistance with mass spectrometry. M.A.C. was the recipient of a George M. Moffett Scholarship from the Whitehall Foundation, New York.

\section{REFERENCES}

BaKshi, Y. K. \& Williams, R. P. (1969). Biosynthesis of protocatechuic acid by non-proliferating cells of Bacillus anthracis. Bacteriological Proceedings, p. 145.

Boulton, A. A. \& Bush, I. E. (1964). Qualitative and quantitative analysis of amino acids as their 'dansyl' derivatives. Biochemical Journal 92, I I P.

Breed, R. S., Murray, E. G. D. \& Smith, N. R. (1957). Bergey's Manual of Determinative Bacteriology, 7 th edn. London: Baillière, Tindall and Cox.

Brennan, P. J., Lehane, D. P. \& Thomas, D. W. (1970). Acylglucoses of the corynebacteria and mycobacteria. European Journal of Biochemistry 13, I $17-123$.

BRot, N., Goodwin, J. \& FALES, H. (I966). In vivo and in vitro formation of 2,3-dihydroxybenzoylserine by Escherichia coli $\mathrm{K}$ 12. Biochemical and Biophysical Research Communications 25, 454-461.

Cagle, C. \& Williams, R. P. (I969). Production of protocatechuic acid by Bacillus cereus. Bacteriological Proceedings, p. I46.

Chao, K. C., Hawkins, D. \& Williams, R. P. (1967). Production of protocatechuic acid by non-proliferating suspensions of Bacillus anthracis. Bacteriological Proceedings, p. $3 \mathrm{I}$.

Chesters, C. G. C. \& Rolinson, G. N. (195I). Trace elements and streptomycin production. Journal of General Microbiology 5, 559-565.

Corbin, J. L. \& Bulen, W. A. (1969). The isolation and identification of 2,3-dihydroxybenzoic acid and 2- $N, 6-N$-Di-(2,3-dihydroxybenzoyl)-L-lysine formed by iron-deficient Azotobacter vinelandii. Biochemistry $8,757-762$.

Cross, T. (1968). Thermophilic actinomycetes. Journal of Applied Bacteriology 3I, 36-53.

Dawson, R. M. C., Elliot, D. C., Elliot, W. H. \& Jones, K. M. (1959). Data for Biochemical Research. Oxford University Press.

Dhople, A. M., Morrison, N. E. \& HANKS, J. H. (I965). Effect of iron limitation on the production of salicylic acid and bound hydroxylamine by Mycobacterium phlei. Bacteriological Proceedings, p. 56.

Donald, C., PASSEY, B. J. \& Swaby, R. J. (1952). A comparison of methods for removing trace metals from microbiological media. Journal of General Microbiology 7, 2 I I-220.

DOWNer, D. N., Davis, W. B. \& BYers, B. R. (1970). Repression of phenolic acid-synthesizing enzymes and its relation to iron uptake in Bacillus subtilis. Journal of Bacteriology 1or, I8I-187.

Dyer, J. R., Heding, H. \& Schaffer, C. P. (1964). Phenolic metabolite of 'low-iron fermentation' of Streptomyces griseus. Characterization of 2,3-dihydroxybenzoic acid. Journal of Organic Chemistry 29, 2802-2803.

Ito, T. \& NeILANDS, J. B. (1958). Products of 'low-iron fermentation' with Bacillus subtilis: isolation, characterization and synthesis of 2,3-dihydroxybenzoylglycine. Journal of the American Chemical Society 8o, 4645-4647.

JENSEN, H. L. (I966). Some introductory remarks on the coryneform bacteria. Journal of Applied Bacteriology 29, I3-16.

KoRTH, H. (1970). Über das Vorkommen von 2,3-Dihydroxybenzoesäure und ihrer Aminosäurederivate in Kulturmedien von Klebsiella oxytoca. Archiv für Mikrobiologie 70, 297-302.

LeCheValier, H. A. \& Lechevalier, M. P. (1967). Biology of actinomycetes. Annual Review of Microbiology 2I, 7I-100. 
LUKE, R. H. J. (1970). Studies on the biosynthesis of 2,3-dihydroxybenzoic acid and related compounds in Escherichia coli $\mathrm{K}$ 12. Ph.D Thesis, The Australian National University, Canberra, Australia.

McGeer, E. G., Robertson, M. C. \& MCGeer, P. L. (196I). Chromatographic characteristics of some aromatic compounds of biological interest. Canadian Journal of Biochemistry and Physiology 96, 605-627.

NeILANDS, J. B. (1966). Naturally occurring non-porphyrin iron compounds. Structure and Bonding I, 59-108.

O'BrIEN, I. G. \& GIBSON, F. (1970). The structure of enterochelin and related 2,3-dihydroxy- $N$-benzoyl serine conjugates from Escherichia coli. Biochimica et biophysica acta 215, 393-402.

Peters, W. J. \& WARren, R. A. J. (1968). Phenolic acids and iron transport in Bacillus subtilis. Biochimica et biophysica acta $165,225-232$.

Pollack, J. R. \& NeILANDS, J. B. (1970). Enterobactin, an iron transport compound from Salmonella typhimurium. Biochemical and Biophysical Research Communications 38, 989-992.

RATLEDGE, C. (1964). Relationship between the products of aromatic biosynthesis in Mycobacterium smegmatis and Aerobacter aerogenes. Nature, London 203, 428-429.

RATLEDGE, C. (1967). The production of an $N$-acylanthranilic acid from shikimic acid and the effect of iron deficiency on the biosynthesis of other aromatic compounds by Aerobacter aerogenes. Biochimica et biophysica acta 14r, 55-63.

RATLEDGE, C. \& HALL, M. J. (1970). Uptake of salicylic acid into mycobactin s by growing cells of Mycobacterium smegmatis. FEBS Letters 10, 309-312.

RATLEDGE, C. \& WINDER, F. G. (1962). The accumulation of salicylic acid by mycobacteria during growth on an iron-deficient medium. Biochemical Journal 84, 501-506.

RATLEDGE, C. \& Winder, F. G. (1966). Biosynthesis and utilization of aromatic compounds by $M y c o-$ bacterium smegmatis with particular reference to the origin of salicylic acid. Biochemical Journal ror, 274-283.

Sмгтн, I. (1960). Chromatographic and Electrophoretic Techniques. Vol. I: Chromatography. London: Heinemann.

SNow, G. A. (1965). Isolation and structure of mycobactin T, a growth factor from Mycobacterium tuberculosis. Biochemical Journal 97, I66-175.

SNow, G. A. (1970). Mycobactins: iron-chelating growth factors from mycobacteria. Bacteriological Reviews 34, 99-125.

SNow, G. A. \& WhITE, A. J. (1969). Chemical and biological properties of mycobactins isolated from various mycobacteria. Biochemical Journal II5, 103I-1045.

WANG, C. C. \& Newton, A. (1969). Iron transport in Escherichia coli: roles of energy-dependent uptake and 2,3-dihydroxybenzoylserine. Journal of Bacteriology 98, I I42-I I 50.

White, A. J. \& SNow, G. A. (1968). Methods for the separation and identification of mycobactins from various species of mycobacteria. Biochemical Journal 108, 593-597.

Zahner, H., BachmanN, E., Hutter, R. \& NuesCh, J. (1962). Sideramine, iron-containing growth factors from micro-organisms. Pathologica et microbiologia 25, 708-726. 